\title{
Reproducibility of dynamic cerebral autoregulation parameters: a multi- centre, multi-method study
}

\section{Authors}

Marit L. Sanders ${ }^{1}$, Jurgen A.H.R. Claassen ${ }^{1}$, Marcel Aries ${ }^{2}$, Edson Bor-Seng-Shu ${ }^{3}$, Alexander Caicedo ${ }^{4}$, Max Chacon ${ }^{5}$, Erik D. Gommer ${ }^{6}$, Sabine Van Huffel ${ }^{4}$, José L. Jara ${ }^{5}$, Kyriaki Kostoglou ${ }^{7}$, Adam Mahdi ${ }^{8}$, Vasilis Z. Marmarelis ${ }^{9}$, Georgios D. Mitsis ${ }^{10}$, Martin Müller ${ }^{11}$, Dragana Nikolic ${ }^{12}$, Ricardo C. Nogueira ${ }^{3}$, Stephen J. Payne ${ }^{8}$, Corina Puppo ${ }^{13}$, Dae C. Shin ${ }^{9}$, David M. Simpson ${ }^{12}$, Takashi Tarumi ${ }^{14}$, Bernardo Yelicich ${ }^{13}$, Rong Zhang ${ }^{14}$, Ronney B. Panerai ${ }^{15}$, Jan Willem J. Elting ${ }^{2}$

${ }^{1}$ Department of Geriatric Medicine, Radboud Alzheimer Centre and Donders Institute for Brain, Cognition and Behaviour, Radboud University Medical Center, The Netherlands

${ }^{2}$ Department of Neurology, University Medical Center Groningen, The Netherlands

${ }^{3}$ Department of Neurology, Hospital das Clinicas University of Sao Paulo, Brazil

${ }^{4}$ Department of Electronic Engineering (ESAT), STADIUS Center for Dynamical Systems, Signal Processing and Data Analytics, KU Leuven, Belgium; imec, Leuven, Belgium

${ }^{5}$ Department of Engineering Informatics, University of Santiago, Chile

${ }^{6}$ Department of Clinical Neurophysiology, University Hospital Maastricht, Netherlands

${ }^{7}$ Department of Electrical, Computer and Software Engineering, McGill University, Montreal, Canada

${ }^{8}$ Department of Engineering Science, University of Oxford, UK

${ }^{9}$ Department of Biomedical Engineering, University of Southern California, Los Angeles, USA

${ }^{10}$ Department of Bioengineering, McGill University, Montreal, Canada

${ }^{11}$ Department of Neurology, Luzerner Kantonsspital, Switzerland 
${ }^{12}$ Institute of Sound and Vibration Research, University of Southampton, UK

${ }^{13}$ Departamento de Emergencia, Hospital de Clínicas, Universidad de la República, Montevideo, Uruguay

${ }^{14}$ IEEM, Presbyterian Hospital Dallas, University of Texas Southwestern Medical Center, USA

${ }^{15}$ Department of Cardiovascular Sciences and Leicester NIHR Biomedical Research Centre in Cardiovascular Sciences, Glenfield Hospital, Leicester, UK

E-mail: Marit.Sanders@ radboudumc.nl 


\section{Abstract}

Objective: Different methods to calculate dynamic cerebral autoregulation (dCA) parameters are available. However, most of these methods demonstrate poor reproducibility that limit their reliability for clinical use. Inter-centre differences in study protocols, modelling approaches and default parameter settings, have all led to a lack of standardisation and comparability between studies. We evaluated reproducibility of dCA parameters by assessing systematic errors in surrogate data resulting from different modelling techniques. Approach: Fourteen centres analysed 22 datasets consisting of two repeated physiological blood pressure measurements with surrogate cerebral blood flow velocity signals, generated using Tiecks curves (autoregulation index , ARI 0-9) and added noise. For reproducibility, dCA methods were grouped in three broad categories: 1 . Transfer function analysis (TFA)-like output; 2. ARI-like output; 3. Correlation coefficient-like output. For all methods, reproducibility was determined by one-way Intraclass Correlation Coefficient analysis (ICC). Main results: For TFA-like methods the mean (SD; [range]) ICC gain was $0.71(0.10 ;[0.49-0.86])$ and 0.80 $(0.17 ;[0.36-0.94])$ for VLF and LF ( $p=0.003)$ respectively. For phase, ICC values were $0.53(0.21$; [0.09-0.80]) for VLF, and $0.92(0.13 ;$ [0.44-1.00]) for LF ( $\mathrm{p}<0.001)$. Finally, ICC for ARI-like methods was equal to $0.84(0.19 ;$ [0.41-0.94]), and for correlation-like methods , ICC was $0.21(0.21$; $[0.056-0.35])$

Significance: When applied to realistic surrogate data, free from the additional exogenous influences of physiological variability on cerebral blood flow, most methods of dCA modelling showed ICC values considerably higher than what has been reported for physiological data. This finding suggests that the poor reproducibility reported by previous studies may be mainly due to the inherent physiological variability of cerebral blood flow regulatory mechanisms rather than related to (stationary) random noise and the signal analysis methods.

Keywords: Cerebral Autoregulation; method comparison; reproducibility; surrogate data 


\section{Introduction}

Cerebral autoregulation (CA) is an important mechanism for maintaining adequate cerebral perfusion despite changes in blood pressure (BP) (Panerai, 1998). Dynamic CA (dCA) is measured as the CBF response to a transient, short-lasting change in BP (Aaslid et al., 1989, Panerai, 1998). Usually, CBF velocity (CBFV) measured with transcranial Doppler ultrasound, as an estimate of CBF, is analysed simultaneously with BP recordings (Panerai et al., 1998b).

Different indices of dCA have been shown to reflect pathological conditions such as stroke, severe head injury, subarachnoid haemorrhage, carotid artery disease and others (Czosnyka et al., 2009, Reinhard et al., 2003b, Reinhard et al., 2004, Reinhard et al., 2012, Immink et al., 2005, Panerai, 2008, van Beek et al., 2008). However, despite the potential to bring considerable benefits to early diagnosis, management and prognosis of patients with cerebrovascular disease, the reliability of these indices of dCA has not been fully validated. Not surprisingly therefore, dCA measurements have not yet been incorporated into routine clinical practice. There are a number of reasons for this.

First, currently no gold standard test for the assessment of dCA exists. Many different methods to calculate dCA parameters are now available and with the growing number of possibilities to measure and analyse $\mathrm{dCA}$, more information is needed about the diagnostic performance and reliability of different methods (Meel-van den Abeelen et al., 2014b, van Beek et al., 2008, Panerai, 2008).

Second, the reproducibility of dCA indices is a major concern; a relatively small number of studies show that most techniques do not demonstrate reproducibility that would be acceptable for clinical use (Gommer et al., 2010, Elting et al., 2014a, van Beek et al., 2010).

Third, a lack of metric convergence between different methods (Tzeng et al., 2012), inter-centre differences in study protocols, modelling approaches and default parameter settings, for techniques such as transfer function analysis (TFA) have led to a lack of standardisation and comparability of studies, thus limiting the possibility of using the literature to overcome the problems above (Meel-van den Abeelen et al., 2014b). 
To address these issues, The Cerebral Autoregulation Research Network (CARNet, www.carnet.org.uk) has embarked on several multi-centre studies aiming to improve standardisation and reliability of techniques for assessment of dCA. The first initiative was limited to one method - TFA following the observation of considerable disparity in parameter settings and reporting of TFA coherence, gain and phase. In that study, a common dataset was analysed with TFA by multiple centres (Meel-van den Abeelen et al., 2014a). The outcome of that study led to recommendations to improve the standardisation of TFA to assess dCA (Claassen et al., 2016).

The present study is part of a more ambitious CARNet project, wherein we aim to address the question of reproducibility for a wider range of dCA methods, not only TFA, but also time-domain models and correlation-coefficient- based methods (Table 1).

We considered that the reproducibility of dCA has two main components, namely 1) 'methodological noise': systematic errors that are inherent to the methods and modelling techniques, and 2) 'physiological noise': random errors due to physiological variability between repeated measurements or due to noise or artefacts in the recorded signals. In order to advance the field, it is important to study each component separately.

The main purpose of the present study was to address the first possible cause of poor dCA reproducibility: the systematic errors resulting from different modelling techniques proposed for $\mathrm{dCA}$ assessment. To achieve this, we have used surrogate CBF data to reduce and control physiologic variability in repeated dCA measurements. We report herein how reproducibility varies when a single dataset is analysed by different centres using various methods to assess dCA.

Specifically, this study assessed the repeatability of dCA measurements for spontaneous oscillations in $\mathrm{BP}$ and $\mathrm{CBFV}$, under the ideal conditions where the expected $\mathrm{dCA}$ is known and invariant between repeated records, covering the full range of autoregulation from absent to very efficient. This was achieved through simulations of $\mathrm{CBF}$, using physiological (truly recorded) repeated BP signals as input. dCA analysis methods were grouped in three broad categories: 1. TFA-like output; 2. ARI-like output and 3. correlation coefficient-like outputs. 
Table 1. Methods with corresponding output variables per centre

\begin{tabular}{|c|c|c|c|c|c|}
\hline $\begin{array}{l}\text { Centre } \\
\text { number }\end{array}$ & Method & Output Variables & $\begin{array}{l}\text { Method } \\
\text { cate- } \\
\text { gory }\end{array}$ & $\begin{array}{l}\text { Method } \\
\text { group }\end{array}$ & References \\
\hline 2 & $\begin{array}{l}\text { 2.1 Laguerre expansion of } 1^{\text {st }} \text {-order } \\
\text { Volterra kernels, single input }(\mathrm{BP}) \\
\text { 2.2 Laguerre expansion of } 1^{\text {st }} \text {-order } \\
\text { Volterra kernels, dual input (BP, } \\
\mathrm{CO}_{2} \text { ) }\end{array}$ & $\begin{array}{l}\text { Gain }(\mathrm{cm} / \mathrm{s} / \mathrm{mmHg}) \text { and Phase }(\mathrm{rad}) \text { in VLF, LF } \\
\text { Gain }(\mathrm{cm} / \mathrm{s} / \mathrm{mmHg}) \text { and Phase (rad) in VLF, LF }\end{array}$ & $\begin{array}{l}1 \\
1\end{array}$ & 2 & $\begin{array}{l}\text { (Marmarelis, 2004, } \\
\text { Marmarelis et al., } \\
\text { 2014a, Marmarelis et } \\
\text { al., 2013, Marmarelis } \\
\text { et al., 2014b) }\end{array}$ \\
\hline 3 & $\begin{array}{l}\text { 3.1 Transfer Function Analysis } \\
\text { 3.2 Transfer Function Analysis }\end{array}$ & $\begin{array}{l}\text { Coherence, Gain }(\mathrm{cm} / \mathrm{s} / \mathrm{mmHg}) \text {, Phase }(\mathrm{rad}) \text { in } \\
\text { VLF, LF } \\
\text { Coherence, Gain }(\% / \%) \text { in VLF, LF }\end{array}$ & $\begin{array}{l}1 \\
1\end{array}$ & $\begin{array}{l}1 \\
1\end{array}$ & (Zhang et al., 1998) \\
\hline 5 & $\begin{array}{l}\text { 5.1 Transfer Function Analysis } \\
\text { 5.2 Oblique and Orthogonal } \\
\text { Subspace Projections }\end{array}$ & $\begin{array}{l}\text { Coherence, Gain }(\mathrm{cm} / \mathrm{s} / \mathrm{mmHg}) \text {, Phase (rad) in } \\
\text { VLF, LF } \\
\text { Subspace Ratio's }\end{array}$ & $\begin{array}{l}1 \\
3\end{array}$ & 1 & $\begin{array}{l}\text { (Zhang et al., 1998) } \\
\text { (Caicedo et al., 2016) }\end{array}$ \\
\hline 6 & 6.1 Transfer Function Analysis & $\begin{array}{l}\text { Coherence, Gain }(\mathrm{cm} / \mathrm{s} / \mathrm{mmHg}) \text {, Phase }(\mathrm{rad}) \text { in } \\
\text { VLF, LF }\end{array}$ & 1 & 1 & $\begin{array}{l}\text { (Muller et al., 2003, } \\
\text { Muller and Osterreich, } \\
\text { 2014) }\end{array}$ \\
\hline 7 & 7.1 Transfer Function Analysis & $\begin{array}{l}\text { Coherence, Gain }(\mathrm{cm} / \mathrm{s} / \mathrm{mmHg}) \text {, Phase }(\mathrm{rad}) \text { in } \\
\text { VLF, LF }\end{array}$ & 1 & 1 & (Gommer et al., 2010) \\
\hline 11 & $\begin{array}{l}\text { 11.1 Transfer Function Analysis, } \\
\text { 11.2 Transfer Function Analysis } \\
\text { 11.3 Transfer Function Analysis } \\
\text { 11.4 Univariate Transfer Function } \\
\text { Analysis (parametric method) } \\
\text { 11.5 Univariate Impulse Response } \\
\text { (parametric method) } \\
\text { 11.6 Multivariate Transfer Function } \\
\text { Analysis (parametric method) }\end{array}$ & $\begin{array}{l}\text { Coherence, Gain }(\mathrm{cm} / \mathrm{s} / \mathrm{mmHg}) \text {, Phase (rad) in } \\
\text { VLF, LF } \\
\text { Coherence, Gain }(\% / \mathrm{mmHg}) \text {, Phase (rad) in } \\
\text { VLF, LF } \\
\text { Coherence, Gain }(\% / \%) \text { in VLF, LF } \\
\text { Coherence, Gain }(\% / \%) \text {, Phase (rad) in LF } \\
\text { The second filter coefficient }\left(\mathrm{h}_{1}\right) \text { of the } \\
\text { estimated FIR } \\
\text { Gain }(\% / \%) \text { and Phase (rad) for LF band }\end{array}$ & $\begin{array}{l}1 \\
1 \\
1 \\
1 \\
2 \\
1\end{array}$ & $\begin{array}{l}1 \\
1 \\
1 \\
4 \\
9 \\
4\end{array}$ & $\begin{array}{l}\text { (Panerai et al., 2000, } \\
\text { Simpson et al., 2001, } \\
\text { Panerai et al., 1998b) }\end{array}$ \\
\hline 12 & $\begin{array}{l}\text { 12.1 Transfer Function Analysis } \\
\text { 12.2 Autoregulation index } \\
\text { 12.3 Wavelet Coherence Analysis }\end{array}$ & $\begin{array}{l}\text { Coherence, Gain }(\mathrm{cm} / \mathrm{s} / \mathrm{mmHg}) \text {, Phase (rad) in } \\
\text { VLF, LF } \\
\text { ARI } \\
\text { Gain }(\mathrm{cm} / \mathrm{s} / \mathrm{mmHg}) \text { and Phase (rad) in VLF, LF }\end{array}$ & $\begin{array}{l}1 \\
2 \\
1\end{array}$ & $\begin{array}{l}1 \\
6 \\
3\end{array}$ & $\begin{array}{l}\text { (Zhang et al., 1998) } \\
\text { (Panerai et al., 1998b) } \\
\text { (Grinsted et al., 2004, } \\
\text { Torrence and Webster, } \\
\text { 1999) }\end{array}$ \\
\hline 13 & 13.1 Transfer Function Analysis & $\begin{array}{l}\text { Coherence, Gain }(\mathrm{cm} / \mathrm{s} / \mathrm{mmHg}) \text {, Phase }(\mathrm{rad}) \text { in } \\
\text { VLF, LF }\end{array}$ & 1 & 1 & $\begin{array}{l}\text { (Panerai et al., 1998a, } \\
\text { Panerai et al., 1998b) }\end{array}$ \\
\hline 14 & $\begin{array}{l}\text { 14.1 ARX models: } 1 \text { input } \\
\text { 14.2 ARX models: } 2 \text { inputs }\end{array}$ & $\begin{array}{l}\text { Gain }(\mathrm{cm} / \mathrm{s} / \mathrm{mmHg}) \text {, Phase }(\mathrm{rad}) \text { in VLF, LF } \\
\text { Gain }(\mathrm{cm} / \mathrm{s} / \mathrm{mmHg}) \text {, Phase (rad) in VLF, LF }\end{array}$ & $\begin{array}{l}1 \\
1\end{array}$ & $\begin{array}{l}5 \\
5\end{array}$ & $\begin{array}{l}\text { (Mitsis et al., 2002, } \\
\text { Mitsis et al., 2009) }\end{array}$ \\
\hline
\end{tabular}


14.3 Laguerre expansion FIR models, single input (BP)

14.4 Laguerre expansion FIR

models, dual input $\left(\mathrm{BP}, \mathrm{CO}_{2}\right)$

14.5 Transfer function analysis

Gain $(\mathrm{cm} / \mathrm{s} / \mathrm{mmHg})$, Phase (rad) in VLF, LF
Gain $(\mathrm{cm} / \mathrm{s} / \mathrm{mmHg})$, Phase (rad) in VLF, LF
Coherence, Gain $(\mathrm{cm} / \mathrm{s} / \mathrm{mmHg})$, Phase (rad) in
VLF, LF

(Mitsis et al., 2004,

Kostoglou et al., 2014)

(Meel-van den Abeelen et al., 2014a)

Method category: $1=$ TFA-like methods, $2=$ ARI-like methods, $3=$ correlation-like methods; Method group: 1=TFA, 2=Laguerre expansions, 3=Wavelets, 4=IR-filter, 5=ARX, 6=ARI, 7=ARMA-

ARI/ARX, 9=IR-filter, 10=correlation coefficient; VLF: very low frequency; LF: low frequency; BP: blood pressure; FFT: fast Fourier transform; ARI: autoregulation index; ARX: autoregressive model with exogenous input; Centre names are listed in Table 2. Pre-processing settings are listed in Table S7.

\section{Methods}

\section{Subjects}

A database was created from available datasets of cerebral hemodynamic measurements from three of the 14 participating centres listed in Table 2 . For the purpose of this study, only the BP signal was selected and the corresponding CBF signal was ignored and replaced by a generated signal (see below). 22 healthy adults age $66.3 \pm 7.0$ years were selected. Exclusion criteria were uncontrolled hypertension, smoking, cardiovascular disease, diabetes, irregular heart rhythm, transient ischemic attack /stroke or significant pulmonary disease. The study has been carried out in accordance with The Code of Ethics of the World Medical Association (Declaration of Helsinki). Informed consent was obtained of all subjects. 
Table 2: Participating centres and their roles

\begin{tabular}{|c|c|c|c|c|}
\hline Name & Institution & Country & Role & $\begin{array}{l}\text { Centre } \\
\text { Number }\end{array}$ \\
\hline $\begin{array}{l}\text { E Borg-Seng-Shu } \\
\text { RC Nogueira }\end{array}$ & $\begin{array}{l}\text { Department of Neurology, Hospital das } \\
\text { Clinicas } \\
\text { University of Sao Paulo }\end{array}$ & Brazil & Analysis & 1 \\
\hline $\begin{array}{l}\text { VZ Marmarelis } \\
\text { DC Shin }\end{array}$ & $\begin{array}{l}\text { Department of Biomedical Engineering } \\
\text { University of Southern California, Los Angeles }\end{array}$ & USA & Analysis & 2 \\
\hline $\begin{array}{l}\text { R Zhang } \\
\text { T Tarumi }\end{array}$ & $\begin{array}{l}\text { IEEM, Presbyterian Hospital Dallas } \\
\text { University of Texas Southwestern Medical } \\
\text { Center }\end{array}$ & USA & $\begin{array}{l}\text { Analysis } \\
\text { Data Provider }\end{array}$ & 3 \\
\hline RB Panerai & $\begin{array}{l}\text { Department of Cardiovascular Sciences } \\
\text { University of Leicester }\end{array}$ & UK & $\begin{array}{l}\text { Analysis } \\
\text { Data Provider } \\
\text { Trial Coordination }\end{array}$ & 4 \\
\hline $\begin{array}{l}\text { S van Huffel } \\
\text { A Caicedo }\end{array}$ & $\begin{array}{l}\text { Department of Electronic Engineering (ESAT), } \\
\text { STADIUS Center for Dynamical Systems, } \\
\text { Signal Processing and Data Analytics, KU } \\
\text { Leuven, Belgium; imec }\end{array}$ & Belgium & Analysis & 5 \\
\hline M Müller & $\begin{array}{l}\text { Department of Neurology } \\
\text { Luzerner Kantonsspital }\end{array}$ & Switzerland & Analysis & 6 \\
\hline ED Gommer & $\begin{array}{l}\text { Department of Clinical Neurophysiology } \\
\text { University Hospital Maastricht }\end{array}$ & Netherlands & $\begin{array}{l}\text { Analysis } \\
\text { Data Provider }\end{array}$ & 7 \\
\hline $\begin{array}{l}\text { SJ Payne } \\
\text { A Mahdi }\end{array}$ & $\begin{array}{l}\text { Department of Engineering Science } \\
\text { University of Oxford }\end{array}$ & UK & Analysis & 8 \\
\hline $\begin{array}{l}\text { JAHR Claassen } \\
\text { ML Sanders }\end{array}$ & $\begin{array}{l}\text { Department of Geriatric Medicine } \\
\text { Radboud University Nijmegen }\end{array}$ & Netherlands & $\begin{array}{l}\text { Analysis } \\
\text { Data Provider } \\
\text { Trial Coordination }\end{array}$ & 9 \\
\hline $\begin{array}{l}\text { DM Simpson } \\
\text { D Nikolic }\end{array}$ & $\begin{array}{l}\text { Institute of Sound and Vibration Research } \\
\text { University of Southampton }\end{array}$ & UK & $\begin{array}{l}\text { Analysis } \\
\text { Data Provider }\end{array}$ & 11 \\
\hline $\begin{array}{l}\text { JWJ Elting } \\
\text { M Aries }\end{array}$ & $\begin{array}{l}\text { Department of Neurology } \\
\text { University Medical Center Groningen }\end{array}$ & Netherlands & $\begin{array}{l}\text { Analysis } \\
\text { Data Provider } \\
\text { Trial Coordination }\end{array}$ & 12 \\
\hline $\begin{array}{l}\text { C Puppo } \\
\text { B Yelicich }\end{array}$ & $\begin{array}{l}\text { Departamento de Emergencia, Hospital de } \\
\text { ClínicasUniversidad de la República, } \\
\text { Montevideo }\end{array}$ & Uruguay & Analysis & 13 \\
\hline $\begin{array}{l}\text { GD Mitsis } \\
\text { K Kostoglou }\end{array}$ & $\begin{array}{l}\text { Department of Bioengineering } \\
\text { Department of Electrical, Computer and } \\
\text { Software Engineering } \\
\text { McGill University, Montreal }\end{array}$ & Canada & Analysis & 14 \\
\hline
\end{tabular}

Centre 10 withdrew their results from analysis because their method was superseded by recent developments that would disadvantage their original approach. 


\section{Description of datasets}

The three centres that provided the data had similar protocols expecting participants to refrain from nicotine, alcohol and caffeine from midnight prior to the study. Time between the two measurements varied between centres from minutes to a maximum of three months. These interval differences were not considered in the analysis. Datasets consisted of five minutes of beat-to-beat mean BP (digital artery volume clamping) and end-tidal $\mathrm{CO}_{2}$ (etCO $\mathrm{CO}_{2}$, capnography) measurements at rest.

The BP time-series were used to generate surrogate $\mathrm{CBF}$ data, which were expressed as CBFV to allow comparison with physiological data and with the literature in this field. For each BP signal in this set, the original Tiecks curves (ARI 0-9) (Panerai et al., 1998b) were used to generate one surrogate CBFV signal from autoregulation index (ARI) values ranging from ARI=0 (absence of autoregulation) to $\mathrm{ARI}=9$ (best $\mathrm{CA}$ that can be observed). The ARI value used to generate the CBFV

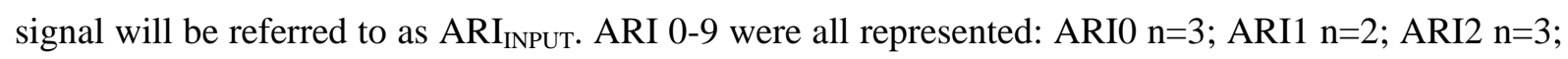
ARI3 =2; ARI4 n=2; ARI5 n=3; ARI6 n=1; ARI7 n=2; ARI8 n=1; ARI9 n=3 (total: $n=22$ ). For the repeated measurements, identical ARI values were used to generate the repeated CBFV signals. Random Gaussian band-pass noise $(0.02-0.1 \mathrm{~Hz})$ was added to the generated CBFV signals, to produce outputs with a signal-to-noise ratio (SNR) of $6 \mathrm{~dB}$ in this frequency range, thus mimicking CBFV signals as they would be measured in 'real life'. (Katsogridakis et al., 2011).

\section{dCA Analysis}

Data analyses were performed by 14 participating centres on 44 datasets from 22 volunteers with two measurements each. The following dCA analysis methods were used: TFA (Reinhard et al., 2003a, Liu et al., 2005, van Beek et al., 2010, Gommer et al., 2010, Panerai, 2014, Mitsis et al., 2002, Zhang et al., 1998, Meel-van den Abeelen et al., 2014a, Muller et al., 2003, Muller and Osterreich, 2014, Panerai et al., 1998a), Laguerre expansion of $1^{\text {st }}$-order Volterra kernels or finite impulse response models (Marmarelis, 2004, Marmarelis et al., 2013, Marmarelis et al., 2014b, Marmarelis et al., 2014a, Mitsis et al., 2004, Mitsis et al., 2009), wavelet analysis (Peng et al., 2010, Torrence and Webster, 1999, Grinsted et al., 2004), parametric finite-impulse response filter based methods (Panerai 
et al., 2000, Simpson et al., 2001), ARI anaysis (Panerai et al., 1998b), autoregressive moving average (ARMA) based ARI methods and variant ARI methods (Panerai et al., 2003), autoregressive with exogenous input (ARX) methods (Liu and Allen, 2002, Liu et al., 2003, Panerai et al., 2003) and correlation coefficient-like indices (Heskamp et al., 2013, Caicedo et al., 2016). A summary of the methods and corresponding references are given in Table 1.

\section{Analysis of dCA outcome parameters}

For the reproducibility and variability analysis of the dCA parameters, analysis methods were grouped into three broad categories: 1. TFA-like output; 2. ARI-like output and 3. correlation coefficient-like outputs. For the TFA-like output methods, we provided suggested settings that were similar to the recent CARNet White Paper (Claassen et al., 2016). However, it should be noted that that paper had not yet been published when we performed this study. Because of this, and given the specific purpose of this study, adherence to these White Paper settings was not strictly enforced. In summary, the suggested settings involved spectral estimates using the Welch method with multiple segments of data of at least $100 \mathrm{~s}, 50 \%$ superposition, and cosine windowing to reduce spectral leakage. Estimates of gain and phase were averaged for different frequency bands. All centres were free to use their own settings to cover the frequency range between $0-0.5 \mathrm{~Hz}$. The ARI-like output methods consisted of time domain estimates of the impulse or step response, using the inverse Fourier transform of gain and phase, or ARMA models. Finally, the correlation coefficient-like outputs consist of a single parameter, obtained by linear regression or similar methods (Table 1). These categories were created from the perspective of similar output parameters, not because of similarity on mathematical grounds.

\section{Statistical analysis}

Reproducibility of the repeated measurements for all dCA analysis methods was determined by oneway Intraclass Correlation Coefficient analysis (ICC). Because the ICC does not reflect the accuracy of the measurement, just the consistency, and because outliers could yield high ICC values, an additional evaluation of accuracy was performed. For this, the results of dCA analysis methods were compared to the reference ARI (ARI INPUT) that was used to generate the surrogate CBFV signals (used 
here as the 'gold-standard' for the simulated signals), and to the reference gain and phase values that corresponded to the ARI INPUT.

Differences between VLF and LF gain and phase values were tested with the paired Wilcoxon signed rank test, considering that most parameters, such as TFA estimates, are not normally distributed. A value of $p<0.05$ was adopted to indicate statistical significance.

\section{Results}

An example showing two BP signals from two different subjects with the corresponding surrogate CBFV signals is presented in Figure 1. This figure shows that the two BP signals differed due to expected physiological variation between repeated measurements, and also demonstrates the difference in the generated CBFV signals between ARI $=0$ (poor autoregulation, high variability in $\mathrm{CBFV}$ ) and $\mathrm{ARI}=9$ (very efficient autoregulation, limited variability in CBFV).
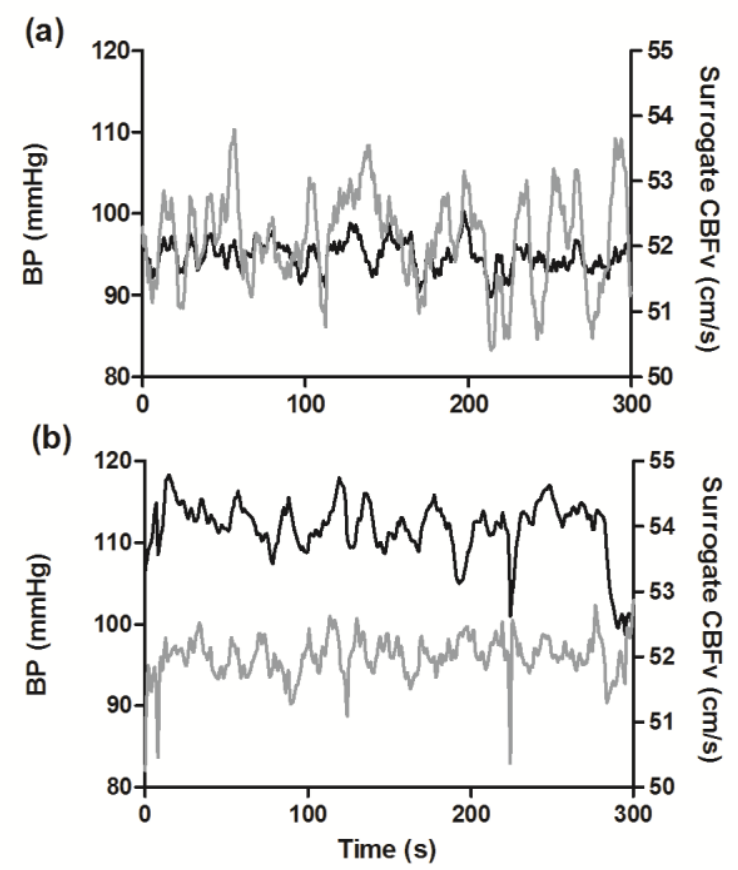
Figure 1. BP and CBFV signal examples. Representative mean blood pressure (BP, black) recordings and their corresponding surrogate cerebral blood flow velocity (CBFV, grey) signals, which were generated using Tiecks' model (Tiecks et al., 1995). In panel (a), ARI 0 was used to generate the CBFV signal, in panel (b) ARI 9 was used. An ARI value of 9 corresponds to very efficient autoregulation which makes the relationship between $\mathrm{BP}$ and $\mathrm{CBFV}$ less pronounced, also considering there is noise added.

\section{ICC}

S2-S6 Tables present an overview of the outcome parameters as reported by all centres and all the different dCA methods that were used for the repeated measurements (T1 and T2).

Figures 2 and 3 depict the results of the ICC analysis. For TFA-like methods (Figure 2), ICC values for gain and phase in the low frequency band (LF: $0.07-0.2 \mathrm{~Hz}$, light grey) are higher than in the very low frequency band (VLF: 0.02-0.07 Hz, dark grey) for almost all methods. Mean (SD; [range]) ICC for gain was $0.71(0.10 ;[0.49-0.86])$ and $0.80(0.17 ;[0.36-0.94])$, respectively for VLF and LF $(\mathrm{p}=0.003)$. For phase, the corresponding ICC values were $0.53(0.21 ;[0.09-0.80])$, and $0.92(0.13$; [0.44-1.00]) respectively $(\mathrm{p}<0.001)$. Figure 3 provides ICC values for ARI-based and correlationbased methods, which provide a single output parameter. Mean (SD; [range]) ICC for ARI-like methods was $0.84(0.19$; [0.41-0.94]). For correlation-like methods, the ICC was $0.21(0.21 ;[0.056-$ $0.35])$. 

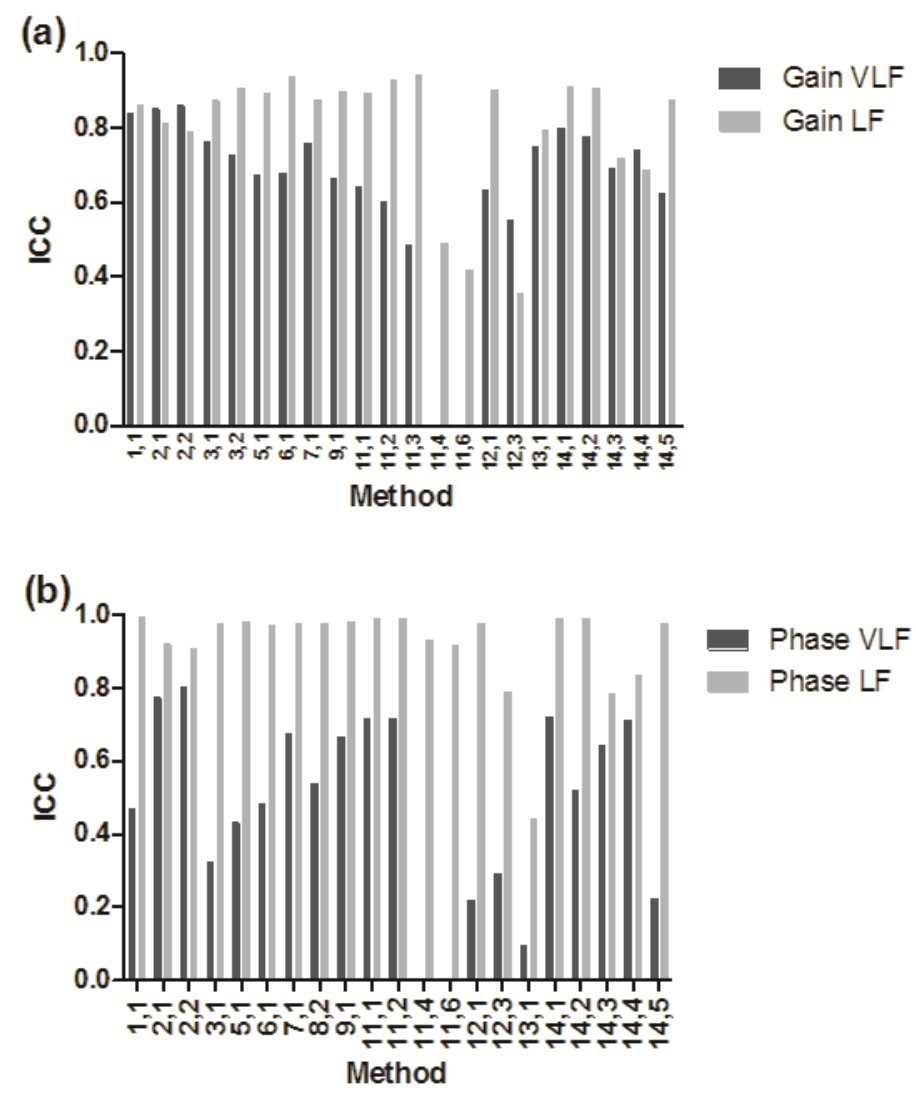

Figure 2. ICC values for methods using TFA or similar approaches ('TFA-like') with multiple outcome parameters. (a): Gain VLF and Gain LF; (b): Phase VLF and Phase LF. Results are shown per method. See Tables 1 and 2 for a list of centres and methods.

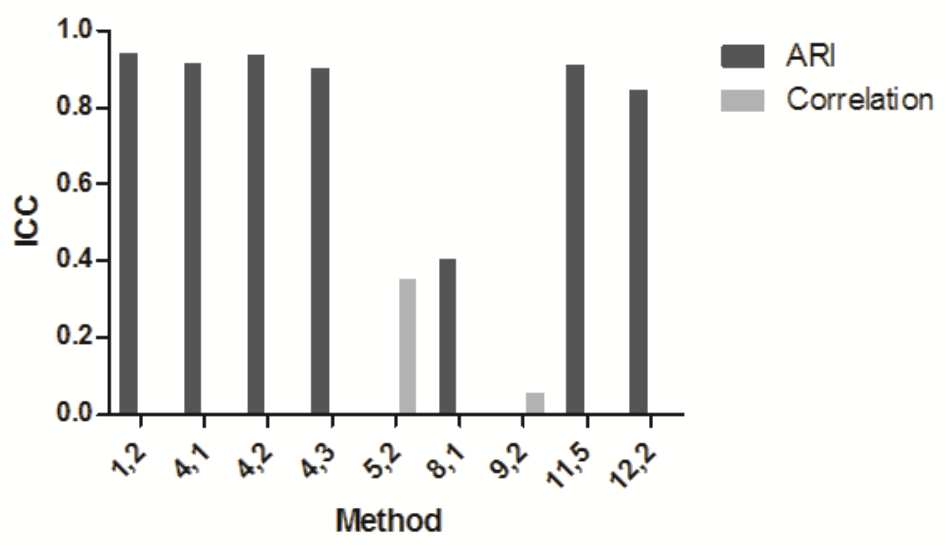

Figure 3. ICC values for methods with single outcome parameters: ARI (dark grey) and correlation based methods (light grey). Results are shown per method. See Tables 1 and 2 for a list of centres and methods. 


\section{Relationship between reference gain, phase, $A R I_{\text {INPUT }}$ and estimated parameters}

In Figure 4, box plots were used to plot the individual outcomes of TFA gain and phase, ARI and correlation coefficient values. The outcomes were pooled and compared against the $\mathrm{ARI}_{\mathrm{INPUT}}$ that was used to generate the surrogate CBFV signals. Overall, a higher ARI INPUT $_{\text {was associated with lower }}$ gain and higher phase outcomes (Figures 4(a-d)). Variation between the gain parameters was larger, compared to phase, especially LF phase, which showed minimal variation between different methods.

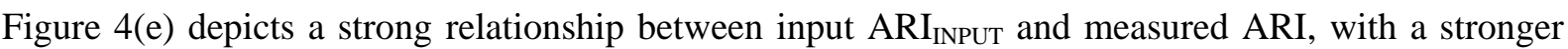
relationship for higher ARI values. On the other hand, there was a lack of association between input $\mathrm{ARI}_{\text {INPUT }}$ and measured correlation coefficient (Figure 4(f)). 
(a)

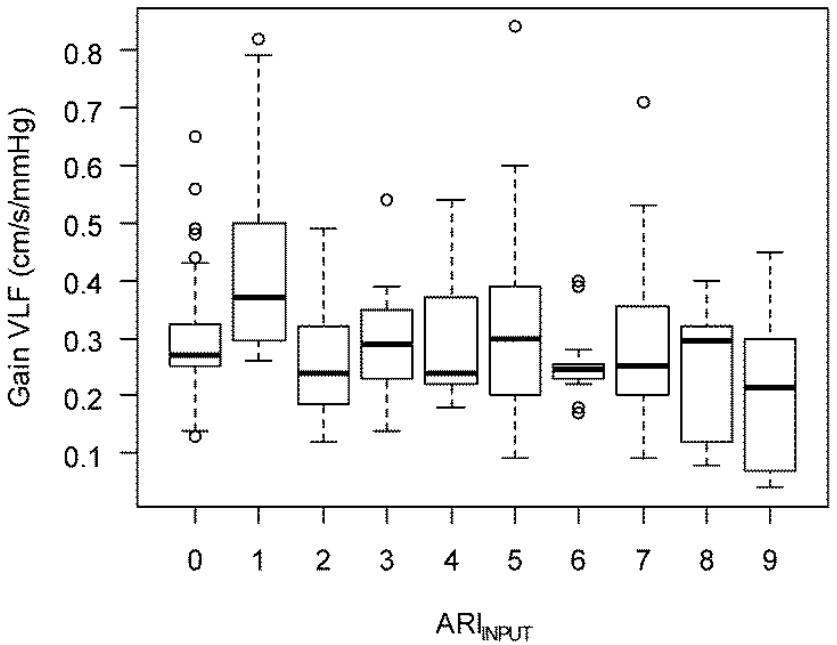

(c)

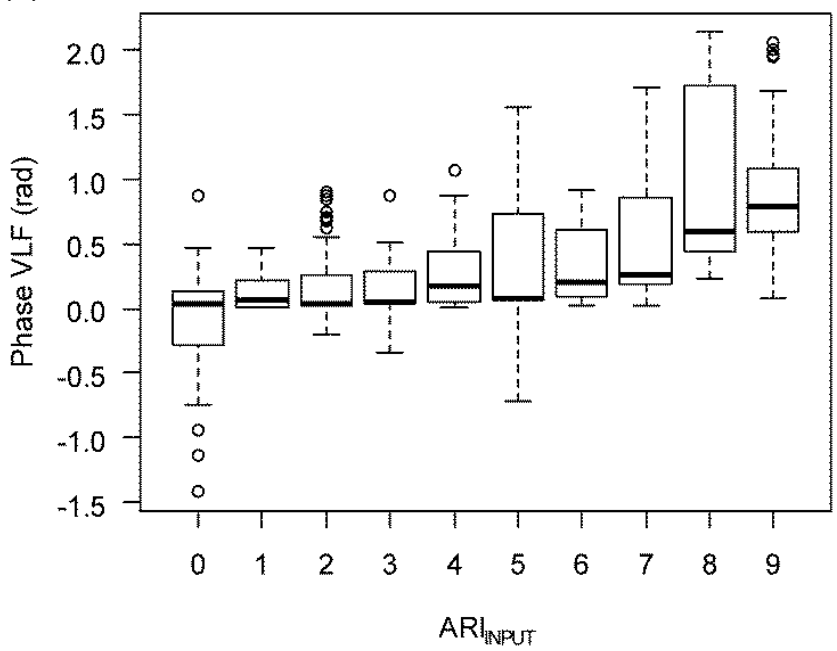

(e)

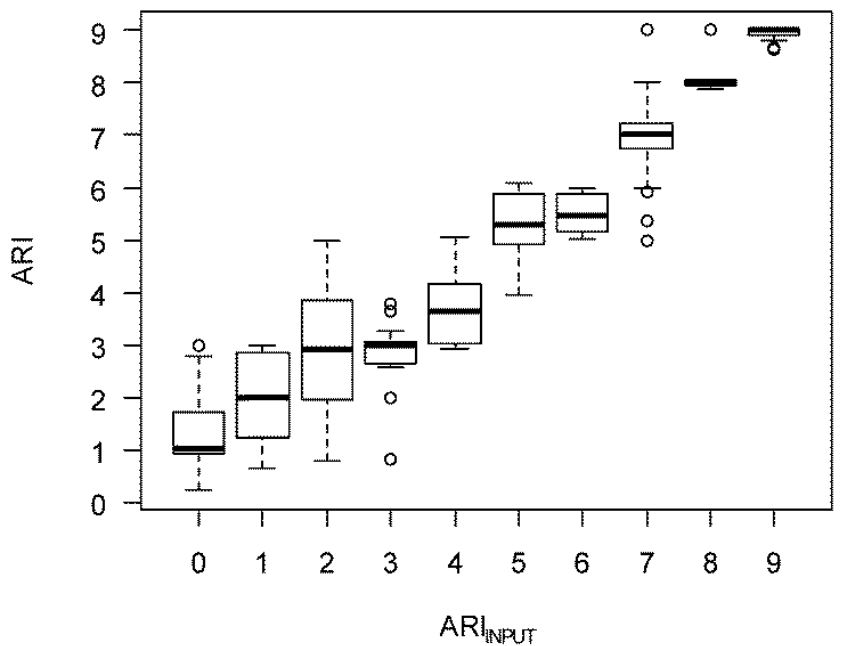

(b)

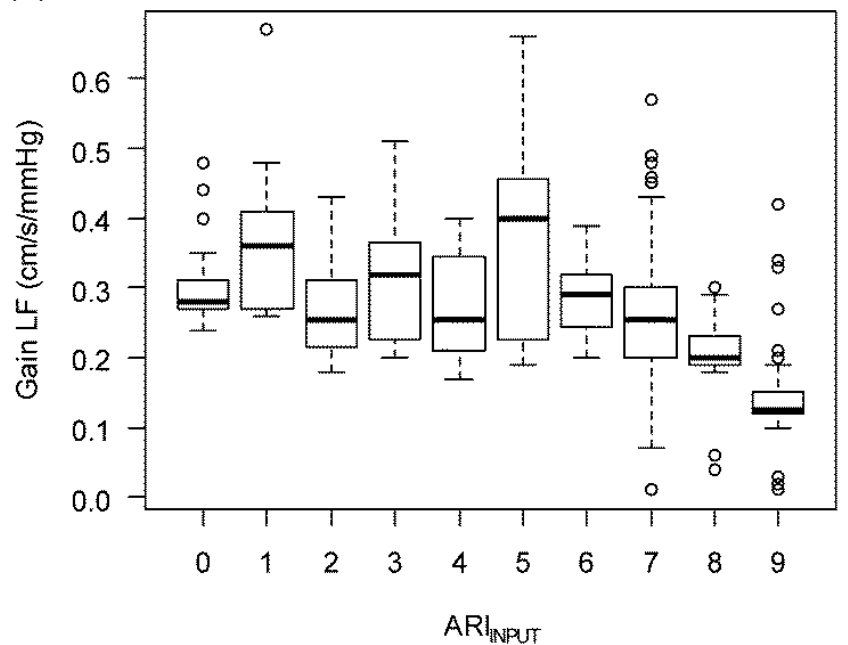

(d)

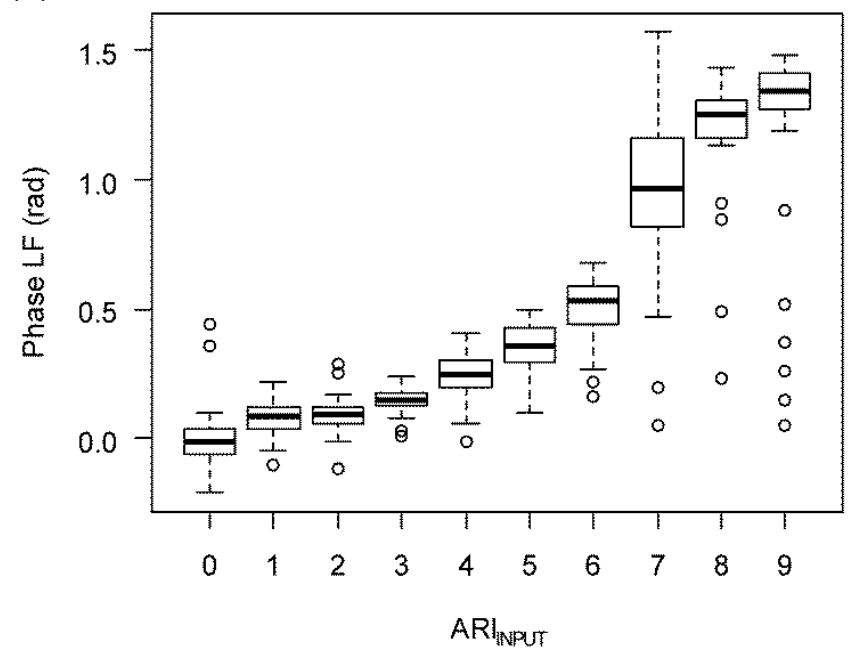

(f)

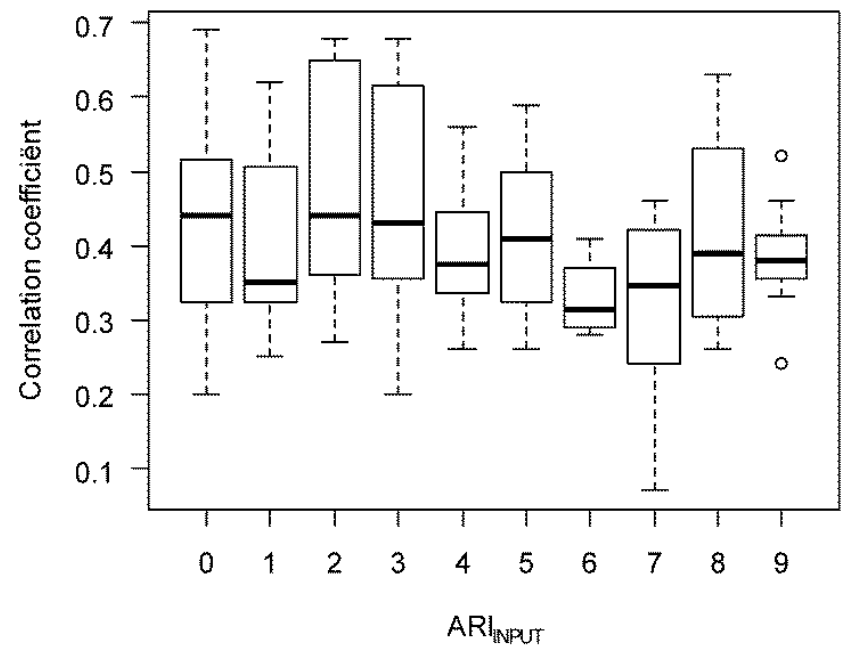

Figure 4. Combined dCA results per method category (Table 1) compared to reference ARI values. TFA gain and phase values, ARI and correlation coefficient values as estimated and reported by 
centres pooled and plotted against the reference $\mathrm{ARI}_{\mathrm{INPUT}}$ value that was used to generate the surrogate CBFV signal. (a): VLF gain; (b): LF gain; (c): VLF phase; (d): LF phase; (e): ARI; (f): Correlation coefficient.

In Figure 5(a-f) averages for each parameter (black lines) are presented in combination with the individual estimated outcomes from each method (grey lines) and are compared to corresponding reference gain, phase, and $\mathrm{ARI}_{\mathrm{INPUT}}$ values. Different methods show similar patterns. In Figures 5(a-b) one method reported systematically shifted gain VLF results, while the other methods yielded more comparable results. The phase VLF results (Figure 5(c)) show more pronounced between-method variability for the lowest and highest phase results. Variability between phase LF measurements (Figure 5(d)) increases with increasing phase. In Figure 5(e) the estimated and reference ARI show a clear association, however in Figure 5(f) any association between estimated correlation coefficient and the reference $\mathrm{ARI}_{\mathrm{INPUT}}$ is lacking. 
(a)

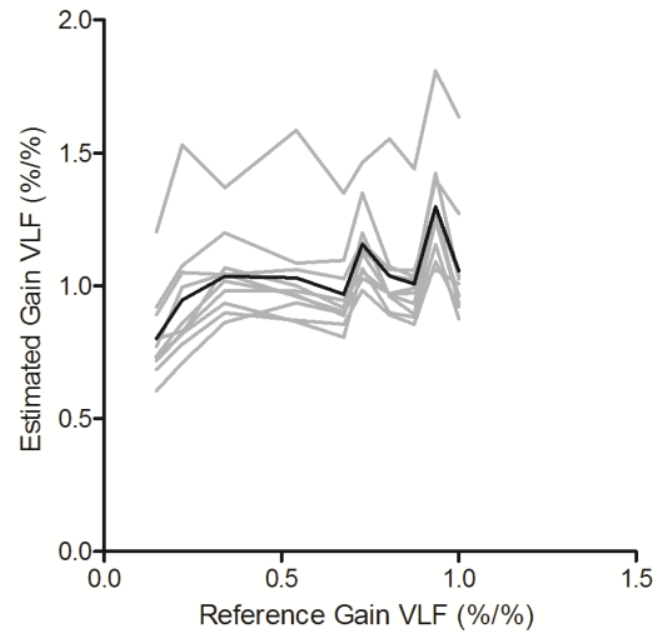

(c)

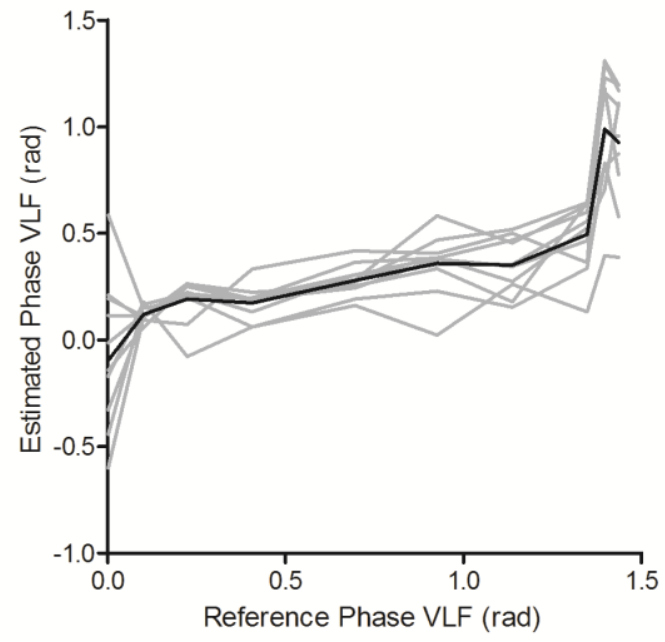

(e)

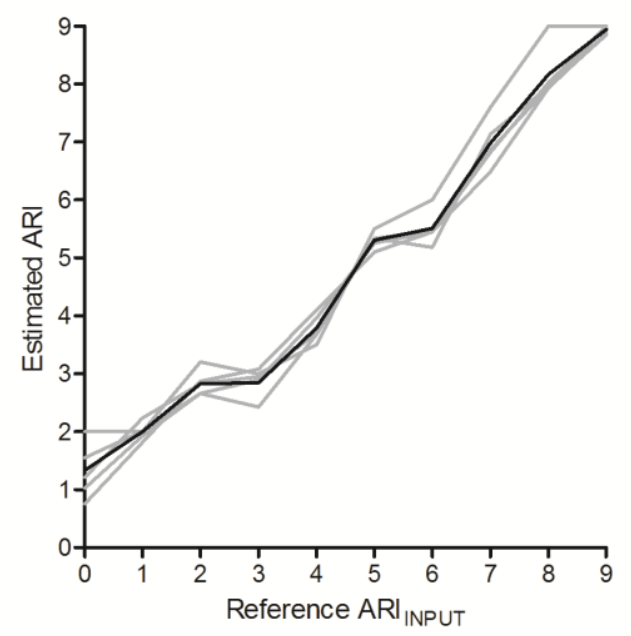

(b)

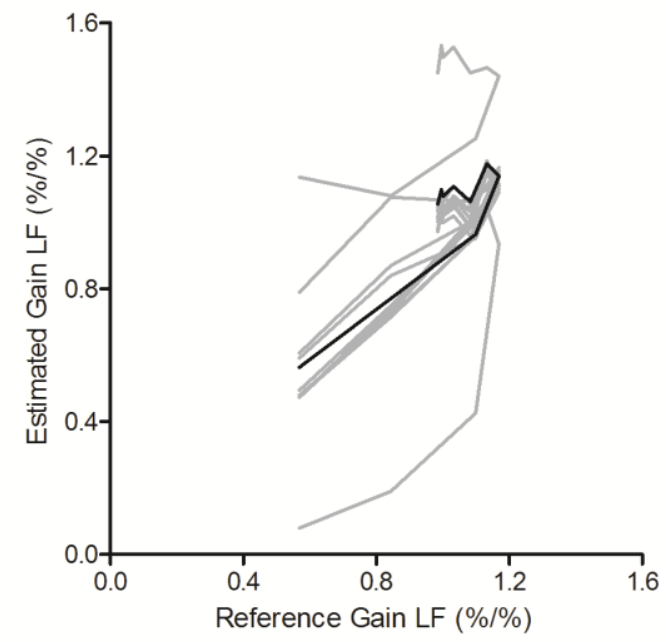

(d)

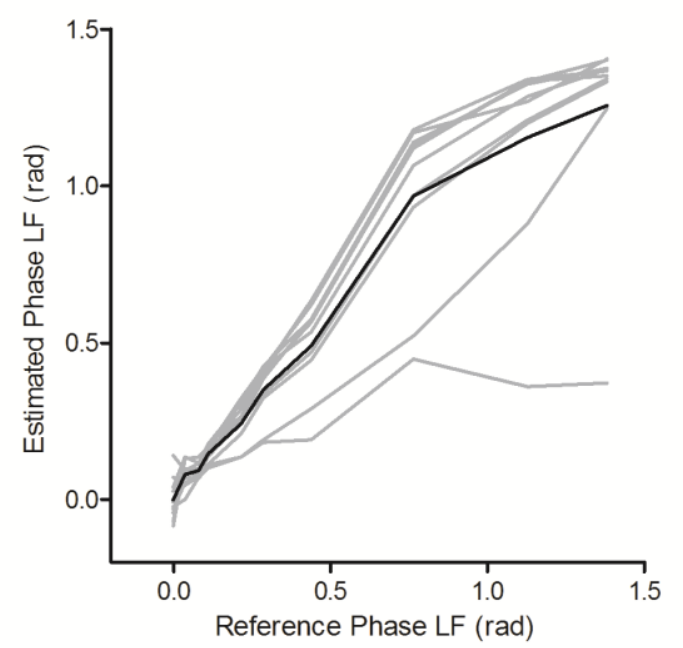

(f)

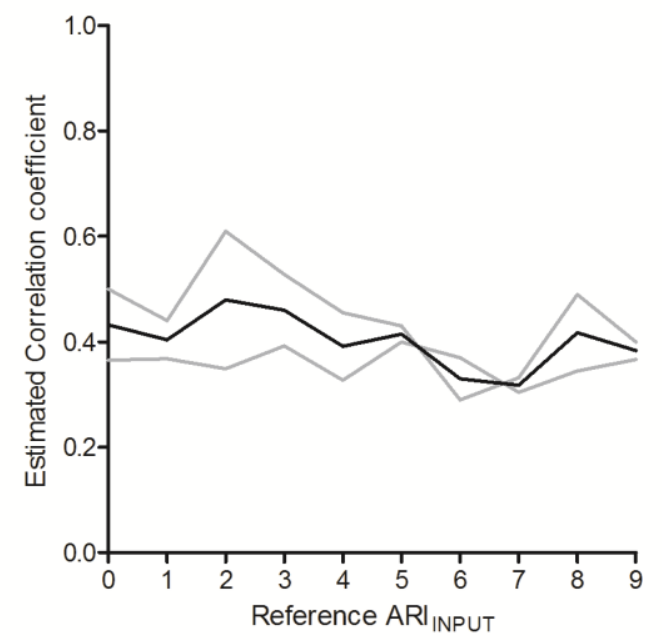


Figure 5. dCA results of individual methods. (a-d): Gain (normalised) and phase, values as estimated and reported by centres plotted against the reference gain and phase values, as depicted in Figure S1, that were determined with standardised CARNet settings (Claassen et al., 2016) (grey lines) and the average of all methods (black line). Figures (e-f): estimated ARI and correlation coefficient values from individual methods against the reference $\mathrm{ARI}_{\mathrm{INPUT}}$ value that was used to generate the surrogate CBFV signal. (a): VLF gain; (b): LF gain; (c): VLF phase; (d): LF phase; (e): ARI; (f): Correlation coefficient.

\section{Discussion}

The main aim of this study was to investigate to what extent shortcomings in methods could be responsible for the high variability (Meel-van den Abeelen et al., 2014a) and therefore poor reproducibility that have been reported in the literature on dCA measurements using spontaneous oscillations (van Beek et al., 2010, Hu et al., 2008, Reinhard et al., 2003a, Gommer et al., 2010, Brodie et al., 2009, Birch et al., 2002). Since poor reproducibility may be explained by physiological variability, combined with methodological shortcomings, we removed the contribution of physiological variability by generating CBFV signals (surrogate output signals) based on true BP recordings as input signals.

\section{Main findings}

Overall, our main finding was that reproducibility, quantified by the ICC, was high for most TFA-like and ARI-like dCA methods for these realistic surrogate data, when compared to previous studies on reproducibility of dCA using physiological data (van Beek et al., 2010, Hu et al., 2008, Reinhard et al., 2003a, Gommer et al., 2010, Brodie et al., 2009, Birch et al., 2002). No single dCA analysis method performed clearly better than others. As a result of these findings, we can conclude that the largest 
contributors to the longitudinal variability of dCA parameters are more likely to be physiological factors, rather than inherent limitations of analytical methods

\section{Assessment of dCA reproducibility}

The choice of ICC as a method to assess reproducibility was based on the difficulty of comparing different methods with multiple outcome parameters. The benefit of using ICC is that it assesses the correlation between repeated measurements in a manner independent of the number or nature of the outcome parameter. On the other hand, one limitation of ICC is that it does not reflect whether these assessments are accurate, i.e. two measurements may both be highly inaccurate but still agree with each other. To account for this, we investigated the agreement of each method by comparing the outcome parameters with the reference ARI (ARI $\left.\mathrm{INPUT}_{\mathrm{IN}}\right)$ that had been used to generate the surrogate

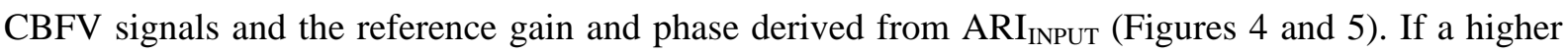
ARI (more efficient autoregulation) is used to generate CBFV signals, the estimated gain based on that signal is expected to be lower (Tiecks et al., 1995). Trends in Figures 4(a), 4(b), 5(a) and 5(b) show this correlation, however the variation is large for both VLF and LF gain. Similarly, phase is expected to be higher for signals generated with higher ARI (Tiecks et al., 1995). Figures 4(c), 4(d), 5(c) and 5(d) show this correlation, with a clearly smaller variation for LF phase. The results of phase and gain estimated by the different methods (Figure 5) were compared to the reference gain and phase values corresponding to the reference ARI INPUT. Supplemental Figure $\mathrm{S} 1$ shows the distribution of phase and gain for each ARI INPUT.

\section{Differences between analytical methods}

The results of the measured ARI values compared to the input ARI show the expected linear correlation (Figure 4(e)) with hardly any deviation from the line of perfect agreement. For the lower ARI values, corresponding to a less efficient or absent autoregulation, the variation is larger. This is in agreement with previous studies describing the increased contribution of the VLF on the ARI estimation for lower ARI values (Elting et al., 2014b). The added noise in the VLF range leads to an increase in variation. The stronger linear relationship between ARI estimates and $\mathrm{ARI}_{\mathrm{INPUT}}$ should not 
in itself be taken as an endorsement of the use of ARI in the assessment of autoregulation in signals recorded from human volunteers. Such a linear relationship might have been expected as ARI was used to generate the surrogate signals. More recent methods, including multivariate analysis, exhibited similar or poorer reproducibility compared to standard TFA and ARI methods. These methods have been partly proposed to overcome problems from time-varying behaviour or the confounding influence of additional inputs, such as $\mathrm{CO}_{2}$ (Marmarelis et al., 2014a, Marmarelis et al., 2013, Marmarelis et al., 2014b, Mitsis et al., 2009, Mitsis et al., 2004, Kostoglou et al., 2014). The simulations did not attempt to emulate these problems and therefore do not show the potential benefit of these methods. The correlation-like methods were underrepresented because only methods that could be applied to short data segments $(5 \mathrm{~min})$ were evaluated, but these clearly showed reduced reproducibility compared to the other categories (Figures 2 and 3) under these conditions. The results obtained with the correlation index were not related to $\mathrm{ARI}_{\mathrm{INPUT}}$, suggesting that the poor reproducibility of these methods for the present dataset may be related to a mismatch in the underlying Tiecks model adopted to generate the surrogate data as explained above. LF phase reproducibility was higher than VLF reproducibility (Figure 2(b)). This also applies, to a lesser extent, to the gain results (Figure 2(a)). The VLF band is more susceptible to the occurrence of large negative values of phase, due to the phenomenon of 'wrap-around' (Claassen et al. 2016). Unless these negative values are removed from the mean, estimates of mean phase for the VLF band will be considerably distorted. VLF gain (Figure 5(a)) showed a difference between the reference value and the measured values for lower gain values, corresponding to higher $\mathrm{ARI}_{\mathrm{INPUT}}$ values. This could be the result of inter-centre differences in pre-processing settings (Table S7). For example, a lack of mean subtraction, a normalisation over the whole data segment or the use of a VLF band including frequencies below $0.02 \mathrm{~Hz}$ could have increased the VLF gain compared to the reference values. Comparing VLF gain and phase line plots (Figure 5(a), 5(c)) with corresponding values for LF (Figure 5(b), 5(d)), a smaller variability is observed in the LF band, especially for the lower ARIs and the agreement between measured output and reference gain and phase is improved in the LF band. These differences between the frequency bands are the result of the added noise that was stronger (in relative terms) in the VLF compared to the LF band. This is also reflected in the low coherence results for VLF in S5 Table. A 
further contributor may also be a lower number of VLF oscillations in both BP and CBFV signals or the different distribution of the theoretical ARI curves for VLF compared to LF.

In summary, different analytical methods for assessment of dCA have different characteristics and peculiarities, but none of the methods included in this study showed distinctive superiority regarding the reproducibility of estimates based on surrogate data. As the next step of this ongoing study, we will investigate the performance of these methods when applied to real physiological measurements.

\section{Limitations of the study}

We used physiological BP data as input. An alternative could have been to first test purely surrogate data with also surrogate BP signals, say with a wide-band spectral power. That should produce the exact systems parameters regardless of the methods used if the surrogate data is generated by a linear system. However, in a future study we aim to compare reproducibility of physiological data with these surrogate data, and therefore the use of physiological BP data in this set was felt to allow better comparison than if we had used purely synthetic data for both BP and CBFV.

To generate realistic CBFV surrogate data, low-pass filtered random noise was added to the output of Tiecks model. The noise power adopted corresponded to a signal-to-noise ratio (SNR) level of $6 \mathrm{~dB}$ as suggested by previous studies (Katsogridakis et al 2011). Most results presented above are likely to change with different levels of SNR. On one hand, much noisier measurements will undoubtedly worsen the ICC and the scatter diagrams (Figure 5), and on the other, high quality measurements could have much better ICC. Both situations deserve more detailed investigation, but, essentially, would not be expected to change the main conclusions of the study, suggesting that the main sources of poor reproducibility lie with the influences of multiple physiological mechanisms, and not with the assessment methods adopted for quantification of dynamic CA. Similar considerations apply to the choice of $0.1 \mathrm{~Hz}$ as cut-off frequency for low-pass filtering the noise added to the CBFV time-series generated with Tiecks model. This choice was based on the power spectral distribution of measured BP and CBFV beat-to-beat values (Mitsis et al 2004; Zhang et al 1998). Different cut-off frequencies are likely to change the results above, but would lead to less realistic CBFV surrogate signals, unless 
non-random sources of noise are considered, for example Doppler probes being disturbed in synchronism with respiratory frequency.

The time interval between repeated measurements that were available varied from same day to several weeks. For the purpose of this study it was not essential to have matching intervals -which would reduce interindividual variability- and therefore this limitation was accepted.

It is difficult to find suitable analysis methods for comparing reproducibility between multiple methods with different outcome values and outcome ranges. Not all criteria for using ICC were met (bivariate normal distributions, and equal variances) which may have influenced the results. However, this influence was reduced by using surrogate CBFV data which do not include external physiological influences except for BP and are free from sporadic artefacts that are common in data recorded from human subjects. For example, ICC is sensitive to outliers, but this would be more of an issue when using purely physiological data. The use of the Tiecks model for the generation of CBFV signals directly influences the results of the non-linear methods, since this model is a linear time-invariant system. Results may thus be biased towards higher reproducibility for linear analysis methods, since non-linear (or time-varying or multivariate) models have additional degrees of freedom that allow more variability, in accordance with the general principle of parsimony in fitting models to data. Such methods might outperform linear ones when the assumptions inherent in the use of linear models are not justified in physiologically 'noisy' data.

The correlation-like methods should be extended with other types of correlation methods to make more extensive analysis feasible for this dCA analysis category. Well known correlation-like methods such as Mx (Czosnyka et al., 1996) were not applicable for this study since longer data recording and ICP data are required.

This study was initiated before the recommendations of the White Paper (Claassen et al., 2016) were formulated. Therefore, the different centres could not be instructed to use standardized settings for TFA. For the purpose of this study, this was not a major limitation because it allowed us better to study the influence of methodological differences on reproducibility. Nonetheless, it also complicated comparisons. For example, there were differences between the frequency band used for the TFA-like 
analysis. Some centres used different settings than the current White Paper recommendations of VLF: 0.02-0.07Hz; LF: $0.07-0.2 \mathrm{~Hz}$; HF: 0.2-0.5 Hz. This again emphasises the need to apply the White Paper standardised settings in future publications on TFA, and to establish consensus on other commonly used methods.

\section{Conclusion}

When applied to realistic surrogate data, free from the influences of physiological variability on the BP-CBF relationship, most methods of dCA modelling yield parameters showing ICC values considerably higher than what has been reported for physiological data. This finding suggests that the poor reproducibility reported by previous studies may be mainly due to the inherent physiological variability of CBF regulatory mechanisms, rather than related to (stationary) random noise and the signal analysis methods. Further work is warranted to test this hypothesis, by comparing the performance of different methods using a common set of repeated recordings, aiming to identify methods that could optimise the reproducibility of dynamic CA parameters while at the same time clearly distinguishing between normal and impaired blood flow regulation. 


\section{References}

AASLID, R., LINDEGAARD, K. F., SORTEBERG, W. \& NORNES, H. 1989. Cerebral autoregulation dynamics in humans. Stroke, 20, 45-52.

BIRCH, A. A., NEIL-DWYER, G. \& MURRILLS, A. J. 2002. The repeatability of cerebral autoregulation assessment using sinusoidal lower body negative pressure. Physiol Meas, 23, 73-83.

BRODIE, F. G., ATKINS, E. R., ROBINSON, T. G. \& PANERAI, R. B. 2009. Reliability of dynamic cerebral autoregulation measurement using spontaneous fluctuations in blood pressure. Clin Sci (Lond), 116, 513-20.

CAICEDO, A., VARON, C., HUNYADI, B., PAPADEMETRIOU, M., TACHTSIDIS, I. \& VAN HUFFEL, S. 2016. Decomposition of Near-Infrared Spectroscopy Signals Using Oblique Subspace Projections: Applications in Brain Hemodynamic Monitoring. Front Physiol, 7, 515.

CLAASSEN, J. A., MEEL-VAN DEN ABEELEN, A. S., SIMPSON, D. M., PANERAI, R. B. \& INTERNATIONAL CEREBRAL AUTOREGULATION RESEARCH, N. 2016. Transfer function analysis of dynamic cerebral autoregulation: A white paper from the International Cerebral Autoregulation Research Network. J Cereb Blood Flow Metab, 36, 665-80.

CZOSNYKA, M., BRADY, K., REINHARD, M., SMIELEWSKI, P. \& STEINER, L. A. 2009. Monitoring of cerebrovascular autoregulation: facts, myths, and missing links. Neurocrit Care, 10, 373-86.

CZOSNYKA, M., SMIELEWSKI, P., KIRKPATRICK, P., MENON, D. K. \& PICKARD, J. D. 1996. Monitoring of cerebral autoregulation in head-injured patients. Stroke, 27, 1829-34.

ELTING, J. W., ARIES, M. J., VAN DER HOEVEN, J. H., VROOMEN, P. C. \& MAURITS, N. M. 2014a. Reproducibility and variability of dynamic cerebral autoregulation during passive cyclic leg raising. Med Eng Phys, 36, 585-91.

ELTING, J. W., MAURITS, N. M. \& ARIES, M. J. 2014b. Variability of the autoregulation index decreases after removing the effect of the very low frequency band. Med Eng Phys, 36, 601-6.

GOMMER, E. D., SHIJAKU, E., MESS, W. H. \& REULEN, J. P. 2010. Dynamic cerebral autoregulation: different signal processing methods without influence on results and reproducibility. Med Biol Eng Comput, 48, 1243-50.

GRINSTED, A., MOORE, J. C. \& JEVREJEVA, S. 2004. Application of the cross wavelet transform and wavelet coherence to geophysical time series. Nonlinear Processes in Geophysics, 11, 561566.

HESKAMP, L., MEEL-VAN DEN ABEELEN, A., KATSOGRIDAKIS, E., PANERAI, R., SIMPSON, D., LAGRO, J. \& CLAASSEN, J. 2013. Convergent cross mapping: a promising technique for future cerebral autoregulation estimation. Cerebrovascular Diseases, 35, 15-16.

HU, K., PENG, C. K., CZOSNYKA, M., ZHAO, P. \& NOVAK, V. 2008. Nonlinear assessment of cerebral autoregulation from spontaneous blood pressure and cerebral blood flow fluctuations. Cardiovasc Eng, 8, 60-71.

IMMINK, R. V., VAN MONTFRANS, G. A., STAM, J., KAREMAKER, J. M., DIAMANT, M. \& VAN LIESHOUT, J. J. 2005. Dynamic cerebral autoregulation in acute lacunar and middle cerebral artery territory ischemic stroke. Stroke, 36, 2595-600.

KATSOGRIDAKIS, E., DINEEN, N. E., BRODIE, F. G., ROBINSON, T. G. \& PANERAI, R. B. 2011. Signal-tonoise ratio of bilateral nonimaging transcranial Doppler recordings of the middle cerebral artery is not affected by age and sex. Ultrasound Med Biol, 37, 530-8.

KOSTOGLOU, K., DEBERT, C. T., POULIN, M. J. \& MITSIS, G. D. 2014. Nonstationary multivariate modeling of cerebral autoregulation during hypercapnia. Med Eng Phys, 36, 592-600.

LIU, J., SIMPSON, D. M. \& ALLEN, R. 2005. High spontaneous fluctuation in arterial blood pressure improves the assessment of cerebral autoregulation. Physiol Meas, 26, 725-41.

LIU, Y. \& ALLEN, R. 2002. Analysis of dynamic cerebral autoregulation using an ARX model based on arterial blood pressure and middle cerebral artery velocity simulation. Med Biol Eng Comput, $40,600-5$. 
LIU, Y., BIRCH, A. A. \& ALLEN, R. 2003. Dynamic cerebral autoregulation assessment using an ARX model: comparative study using step response and phase shift analysis. Med Eng Phys, 25, 647-53.

MARMARELIS, V. Z. 2004. Nonlinear Dynamic Modeling of Physiological Systems, New Jersey, WileyInterscience.

MARMARELIS, V. Z., SHIN, D. C., ORME, M. \& RONG, Z. 2014a. Time-varying modeling of cerebral hemodynamics. IEEE Trans Biomed Eng, 61, 694-704.

MARMARELIS, V. Z., SHIN, D. C., ORME, M. E. \& ZHANG, R. 2013. Model-based quantification of cerebral hemodynamics as a physiomarker for Alzheimer's disease? Ann Biomed Eng, 41, 2296-317.

MARMARELIS, V. Z., SHIN, D. C., ORME, M. E. \& ZHANG, R. 2014b. Model-based physiomarkers of cerebral hemodynamics in patients with mild cognitive impairment. Med Eng Phys, 36, 62837.

MEEL-VAN DEN ABEELEN, A. S., SIMPSON, D. M., WANG, L. J., SLUMP, C. H., ZHANG, R., TARUMI, T., RICKARDS, C. A., PAYNE, S., MITSIS, G. D., KOSTOGLOU, K., MARMARELIS, V., SHIN, D., TZENG, Y. C., AINSLIE, P. N., GOMMER, E., MULLER, M., DORADO, A. C., SMIELEWSKI, P., YELICICH, B., PUPPO, C., LIU, X., CZOSNYKA, M., WANG, C. Y., NOVAK, V., PANERAI, R. B. \& CLAASSEN, J. A. 2014a. Between-centre variability in transfer function analysis, a widely used method for linear quantification of the dynamic pressure-flow relation: the CARNet study. Med Eng Phys, 36, 620-7.

MeEL-VAN DEN ABEelen, A. S., VAN BEeK, A. H., SLUMP, C. H., PANERAl, R. B. \& CLAASSEN, J. A. 2014b. Transfer function analysis for the assessment of cerebral autoregulation using spontaneous oscillations in blood pressure and cerebral blood flow. Med Eng Phys, 36, 56375.

MITSIS, G. D., POULIN, M. J., ROBBINS, P. A. \& MARMARELIS, V. Z. 2004. Nonlinear modeling of the dynamic effects of arterial pressure and $\mathrm{CO} 2$ variations on cerebral blood flow in healthy humans. IEEE Trans Biomed Eng, 51, 1932-43.

MITSIS, G. D., ZHANG, R., LEVINE, B. D. \& MARMARELIS, V. Z. 2002. Modeling of nonlinear physiological systems with fast and slow dynamics. II. Application to cerebral autoregulation. Ann Biomed Eng, 30, 555-65.

MITSIS, G. D., ZHANG, R., LEVINE, B. D., TZANALARIDOU, E., KATRITSIS, D. G. \& MARMARELIS, V. Z. 2009. Autonomic neural control of cerebral hemodynamics. IEEE Eng Med Biol Mag, 28, 5462.

MULLER, M., BIANCHI, O., ERULKU, S., STOCK, C., SCHWERDTFEGER, K. \& HOMBURG TRAUMATIC BRAIN INJURY, G. 2003. Changes in linear dynamics of cerebrovascular system after severe traumatic brain injury. Stroke, 34, 1197-202.

MULLER, M. W. \& OSTERREICH, M. 2014. A comparison of dynamic cerebral autoregulation across changes in cerebral blood flow velocity for 200 s. Front Physiol, 5, 327.

PANERAI, R. B. 1998. Assessment of cerebral pressure autoregulation in humans--a review of measurement methods. Physiol Meas, 19, 305-38.

PANERAI, R. B. 2008. Cerebral autoregulation: from models to clinical applications. Cardiovasc Eng, 8, 42-59.

PANERAI, R. B. 2014. Nonstationarity of dynamic cerebral autoregulation. Med Eng Phys, 36, 576-84.

PANERAI, R. B., EAMES, P. J. \& POTTER, J. F. 2003. Variability of time-domain indices of dynamic cerebral autoregulation. Physiol Meas, 24, 367-81.

PANERAI, R. B., RENNIE, J. M., KELSALL, A. W. \& EVANS, D. H. 1998a. Frequency-domain analysis of cerebral autoregulation from spontaneous fluctuations in arterial blood pressure. Med Biol Eng Comput, 36, 315-22.

PANERAI, R. B., SIMPSON, D. M., DEVERSON, S. T., MAHONY, P., HAYES, P. \& EVANS, D. H. 2000. Multivariate dynamic analysis of cerebral blood flow regulation in humans. IEEE Trans Biomed Eng, 47, 419-23.

PANERAI, R. B., WHITE, R. P., MARKUS, H. S. \& EVANS, D. H. 1998b. Grading of cerebral dynamic autoregulation from spontaneous fluctuations in arterial blood pressure. Stroke, 29, 2341-6. 
PENG, T., ROWLEY, A. B., AINSLIE, P. N., POULIN, M. J. \& PAYNE, S. J. 2010. Wavelet phase synchronization analysis of cerebral blood flow autoregulation. IEEE Trans Biomed Eng, 57, 960-8.

REINHARD, M., MULLER, T., GUSCHLBAUER, B., TIMMER, J. \& HETZEL, A. 2003a. Transfer function analysis for clinical evaluation of dynamic cerebral autoregulation--a comparison between spontaneous and respiratory-induced oscillations. Physiol Meas, 24, 27-43.

REINHARD, M., ROTH, M., MULLER, T., CZOSNYKA, M., TIMMER, J. \& HETZEL, A. 2003b. Cerebral autoregulation in carotid artery occlusive disease assessed from spontaneous blood pressure fluctuations by the correlation coefficient index. Stroke, 34, 2138-44.

REINHARD, M., ROTH, M., MULLER, T., GUSCHLBAUER, B., TIMMER, J., CZOSNYKA, M. \& HETZEL, A. 2004. Effect of carotid endarterectomy or stenting on impairment of dynamic cerebral autoregulation. Stroke, 35, 1381-7.

REINHARD, M., RUTSCH, S., LAMBECK, J., WIHLER, C., CZOSNYKA, M., WEILLER, C. \& HETZEL, A. 2012. Dynamic cerebral autoregulation associates with infarct size and outcome after ischemic stroke. Acta Neurol Scand, 125, 156-62.

SIMPSON, D. M., PANERAI, R. B., EVANS, D. H. \& NAYLOR, A. R. 2001. A parametric approach to measuring cerebral blood flow autoregulation from spontaneous variations in blood pressure. Ann Biomed Eng, 29, 18-25.

TIECKS, F. P., LAM, A. M., AASLID, R. \& NEWELL, D. W. 1995. Comparison of static and dynamic cerebral autoregulation measurements. Stroke, 26, 1014-9.

TORRENCE, C. \& WEBSTER, P. J. 1999. Interdecadal changes in the ENSO-monsoon system. Journal of Climate, 12, 2679-2690.

TZENG, Y. C., AINSLIE, P. N., COOKE, W. H., PEEBLES, K. C., WILLIE, C. K., MACRAE, B. A., SMIRL, J. D., HORSMAN, H. M. \& RICKARDS, C. A. 2012. Assessment of cerebral autoregulation: the quandary of quantification. Am J Physiol Heart Circ Physiol, 303, H658-71.

VAN BEEK, A. H., CLAASSEN, J. A., RIKKERT, M. G. \& JANSEN, R. W. 2008. Cerebral autoregulation: an overview of current concepts and methodology with special focus on the elderly. $J$ Cereb Blood Flow Metab, 28, 1071-85.

VAN BEEK, A. H., LAGRO, J., OLDE-RIKKERT, M. G., ZHANG, R. \& CLAASSEN, J. A. 2012. Oscillations in cerebral blood flow and cortical oxygenation in Alzheimer's disease. Neurobiol Aging, 33, 428 e21-31.

VAN BEEK, A. H., OLDE RIKKERT, M. G., PASMAN, J. W., HOPMAN, M. T. \& CLAASSEN, J. A. 2010. Dynamic cerebral autoregulation in the old using a repeated sit-stand maneuver. Ultrasound Med Biol, 36, 192-201.

ZHANG, R., ZUCKERMAN, J. H., GILLER, C. A. \& LEVINE, B. D. 1998. Transfer function analysis of dynamic cerebral autoregulation in humans. Am J Physiol, 274, H233-41. 